Gut, 1972, 13, 802-804

\title{
An interim report on the production of colonic diverticula in the rabbit
}

\author{
W. J. B. HODGSON \\ From St George's Hospital Medical School, London
}

SUMMARY Six New Zealand white rabbits were given gas induction anaesthetics and maintained on glucochloralose (Merck) $60 \mathrm{mg} / \mathrm{kg}$ given intravenously. Intracolonic pressures were measured after a standard dose of prostigmine, $0.05 \mathrm{mg} / \mathrm{kg}$, using fluid-filled, open-tipped, narrow-bore polythene tubes. Then the rabbits were put on a diet of white bread, butter, milk, and sugar supplemented by vitamins for four months. All six rabbits had put on weight but their general condition deteriorated; they had become constipated and the colon contracted. After stimulation with prostigmine 0.05 $\mathrm{mg} / \mathrm{kg}$ scattered intertaenial wide-necked diverticula appeared which were thinner than the normal haustra and looked like a blackcurrant in colour, size, and shape. Repeat pressure measurements showed that the colonic motility index was increased up to 10 times from predietary levels with a highly significant mean increase from 5299 to 33151 (P < 0.0005).

Wierda (1943) produced solitary diverticula in the proximal colon of three rats by feeding them on high fat diets for 90 to 111 weeks. Each rat had a diverticulum of the colon within $2 \mathrm{~cm}$ of the caecum, and one had a second diverticulum along the length of the large bowel. No colonic diverticula were found in rats on the same diet sacrificed when 25 to 50 weeks old. Carlson and Hoelzel (1949) were able to produce solitary diverticula in the proximal colon of about $20 \%$ of a group of 252 rats in life-span studies on various diets. The diverticula were within $1 \mathrm{~cm}$ of the caecum and usually one but occasionally two or three were produced. Rats on bulky diets showed the least evidence of diverticulosis but diverticula developed in those rats kept on a low residue diet and, more particularly, in those rats which were first fed on a bulky diet and later switched to a low residue diet. Morgan and Ellis (1969) fed 38 black and white Lister rats on a low roughage diet for 52 to 70 weeks. Their diet comprised $\mathbf{6 0 \%}$ sucrose, $20 \%$ casilan, $15 \%$ arachis oil, and $5 \%$ mineral salts and vitamins. No diverticula were produced but the colon was invariably very contracted and contained little food residue.

Pace (1968) stated that apart from man, only the horse, guinea pig, and rabbit had taeniae coli. Ostler (1961) and Greenham (1962), reviewing diseases in the domestic rabbit, did not mention diverticula. Normally the rabbit has a high residue Received for publication 15 December 1971. diet, and indeed its huge caecum is necessary in order partially to digest cellulose. Nocturnal coprophagia also helps in the digestion of cellulose.

Painter (1969) has postulated that half a lifetime with lack of natural fibre in the diet results in diverticular disease. Arfwidsson (1964) showed that intracolonic pressures are raised in the presence of diverticular disease and also that they are raised in the prediverticular state.

Rabbits are suitable sized laboratory animals for the measurement of intracolonic pressures; they have taeniae coli like man, and they normally have a high residue diet. It was decided, therefore, to test the effects of a low residue diet in the rabbit. Furthermore the rabbit is a suitable experimental model for the study of colonic motility and its abnormalities.

\section{Method}

Six New Zealand white rabbits were used and after a gas induction anaesthetic they were given glucochloralose (Merck) $60 \mathrm{mg} / \mathrm{kg}$ intravenously and maintained on oxygen whilst their intracolonic pressures were measured using fluid-filled, opentipped, narrow-bore polythene tubes placed in the proximal and distal colon of the rabbit through a caecostomy. After a resting period of 30 minutes colonic activity was produced using a standard dose of prostigmine $0.05 \mathrm{mg} / \mathrm{kg}$ and the resultant pressure changes were recorded over the next half hour. The 
colon, also, was observed.

Calculations were performed after measuring the width and height of each individual wave from which the results can be expressed in several different ways, the most convenient of which is the colonic motility index (after Chaudhary and Truelove, 1961). The colonic motility index (CMI) is calculated as the sum of the products of the width and height of each wave corrected to a standard time.

After these measurements the rabbits were put on a diet of white bread, butter, milk and sugar, supplemented by vitamins. This diet was chosen because it represents the sort of diet eaten by old people in England. No set quantities were given to the rabbits, because it would be difficult to determine the exact amount of any particular ingredient eaten by the rabbit, and in any case, human beings are not in the habit of measuring exactly the quantities of food they eat, and this is the situation which this experiment is trying to mimic. After varying times on the diet, usually four months, the rabbits were examined again.

\section{Results}

When the normal rabbit colon (in a rabbit on a normal laboratory diet of balanced pellets) is observed, it can be seen that the circular muscle contracts between the taeniae so that it produces a series of transverse grooves. Occasionally, intertaenial areas distend slightly.

On this low residue diet all six of the rabbits put on weight (Fig. 1), but their general condition deteriorated for they lost the shine of their fur. All the rabbits became very constipated, whereas normally rabbits pass large numbers of soft pellets which only harden on drying.

When the rabbits were examined again few adhesions were present but sometimes the colon appeared to be thickened and contracted. The mesentery had become loaded with fat. After stimulation with prostigmine $0.05 \mathrm{mg} / \mathrm{kg}$ scattered intertaenial diverticula appeared (Fig. 2). About three diverticula would occupy a $5 \mathrm{~cm}$ length of colon compared with 12 to 20 haustral segments which normally would occupy this length. The diverticula were wide-necked and appeared regularly in the same spot when that part of the colon contracted. These diverticula were thinner than the normal haustra and looked like a blackcurrant in colour, size, and shape. The normal haustral segments are pink. One rabbit, examined after only two months on a low residue diet, did not produce diverticula. Painter (1964) clearly demonstrated the temporary nature of diverticula in the human colon by using cineradiography and he was able to show

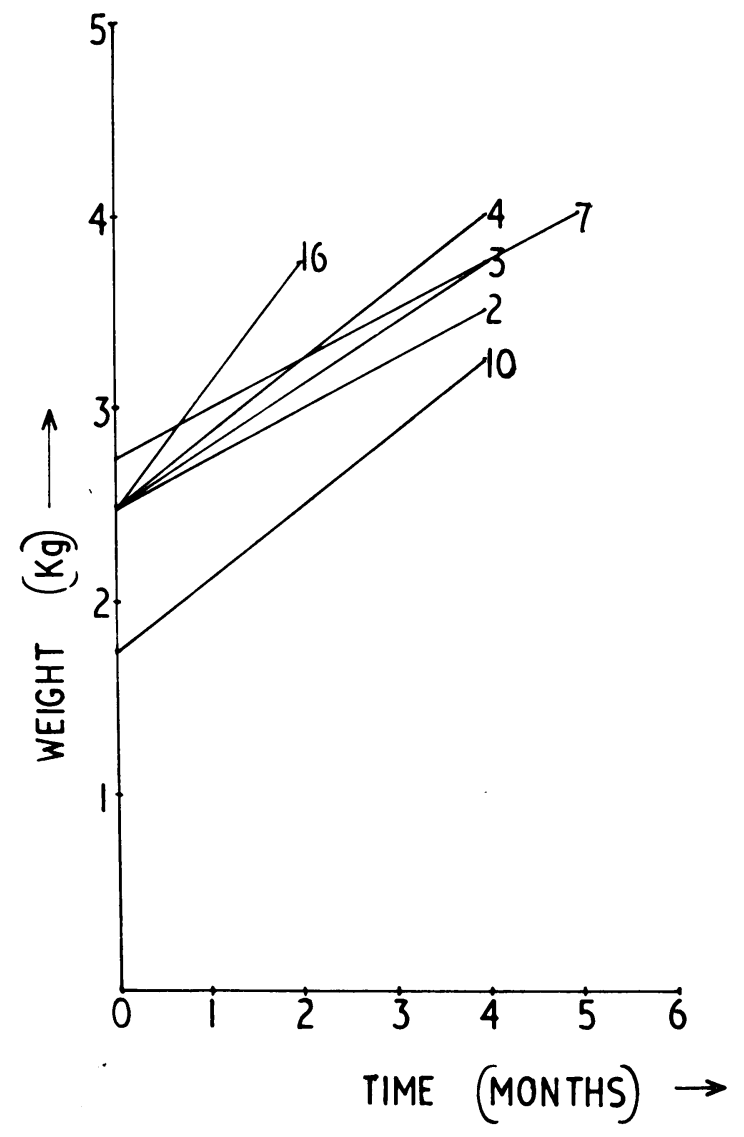

Fig. 1 Weight increase in rabbits on low residue diets.

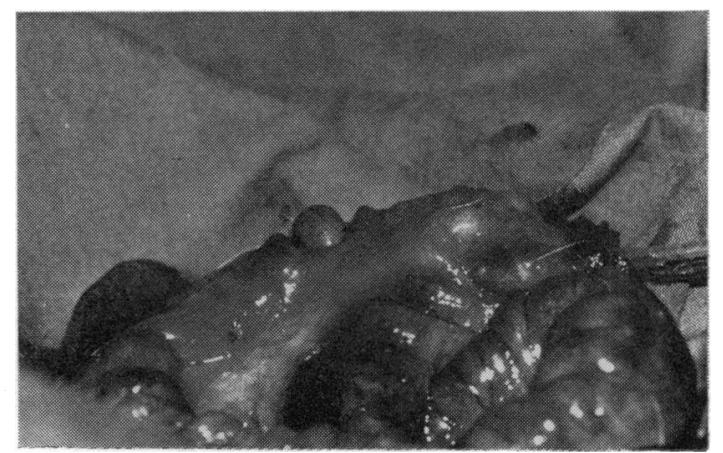

Fig. 2 Diverticula in the rabbit colon after a low residue diet.

that as the segments contracted so a diverticulum was produced which may disappear as that segment relaxes. The diverticula produced in the rabbit colon did not appear to be any different from those described by Painter in man. 


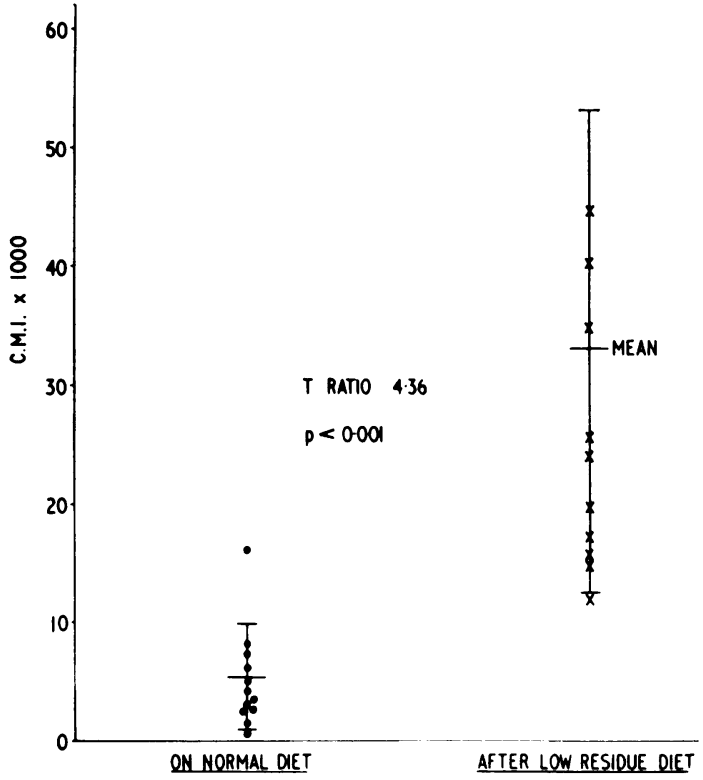

Fig. 3 Effect on colonic motility index of rabbit colon after four months on low residue diet.

Repeat pressure measurements again performed on both proximal and distal colon showed that the colonic motility index in these rabbits was up to 10 times greater than that in the same rabbits on initial testing (Fig. 3). Even in the rabbit which did not have time to produce diverticula its colonic activity was raised above its pre-diet level. The $t$ ratio on 22 degrees of freedom was 4.36 for the difference of the CMI means in the rabbit colon before and after the low residue diet. Student's $t$ test shows a highly significant difference with P less than 0.0005 or $2 \mathrm{P}$ less than 0.001 .

\section{Discussion}

Feeding New Zealand white rabbits with a low residue diet of bread, butter, milk, and sugar produces colonic diverticula after the relatively short period of four months. Vitamins were the only added requirements. These foods supply necessary carbohydrates, fat, protein, and energy, and are much more indicative of the type of diet eaten by civilised man than the artificial diets used by Wierda (1943), Carlson and Hoelzel (1949) and also by Morgan and Ellis (1969).

The rabbit was chosen for this study because of the similarity of its colon to that of man. It is an interesting observation that the horse, guinea pig, and rabbit are all herbivorous, and therefore, normally have a very high residue diet. Perhaps the colon of man was designed for the same type of diet. Indeed, Painter (1969) has postulated that it is this very lack of natural fibre in the diet that leads to diverticular disease. The results so far obtained in these experiments strongly support this theory.

Arfwidsson (1964) showed that intracolonic pressures are raised in the prediverticular state as well as in diverticular disease. One rabbit had raised pressures but had not produced diverticula after only two months on a low residue diet. All the other rabbits show very great pressure increases after four months on a low residue diet when stimulated with prostigmine and this correlates very closely to the findings in man when patients with diverticular disease are given prostigmine (Painter, 1964; Arfwidsson, 1964).

It is shown that a low residue diet leads to raised intracolonic pressures in the rabbit and it is possible that these raised pressures result in areas of weakness in the circular muscle corresponding to the distribution of blood vessels so that diverticula are formed at these areas when the colon undergoes a contraction.

This work has been carried out by a scholarship endowed by the Governors of Charing Cross Hospital and is to be part of the M.S. (London) thesis. I would like to thank the Governors and Professor A. J. Harding Rains for their backing of this project, Mr A. G. Johnson for his advice, and Mrs J. Pheasant, Miss K. Marsh, Mr C. Kirk, and Mr N. Harling for their technical assistance; and also Miss Turnbull for her excellent photography.

\section{References}

Arfwidsson, S. (1964). Pathogenesis of multiple diverticula of the sigmoid colon in diverticular disease. Acta chir. scand., Suppl. 342 .

Carlson, A. J., and Hoelzel, F. (1949). Relation of diet to diverticulosis of the colon in rats. Gastroenterology, 12, 108-115.

Chaudhary, N. A., and Truelove, S. C. (1961). Human colonic motility: a comparative study of normal subjects, patients with ulcerative colitis and patients with the irritable colon syndrome. Gastroenterology, 40, 1-36.

Greenham, L. W. (1962). Some preliminary observations on rabbit mucoid enteritis. Vet. Rec., 74, 79-84.

Morgan, N. M., and Ellis, H. (1969). Diverticulosis of the colon and diet. Brit. med. J., 2, 53-54.

Ostler, D. C. (1961). The diseases of broiler rabbits. Vet. Rec., 73, 1237-1254.

Pace, J. L. (1968). The anatomy of the haustra of the human colon. Proc. roy. Soc. Med., 61, 934-935.

Painter, N. S. (1964). The aetiology of diverticulosis of the colon with special reference to the action of certain drugs on the behaviour of the colon. Ann. roy. Coll. Surg. Engl., 34, 98-119.

Painter, N. S. (1969). Diverticular disease of the colon. A disease of this century. Lancet, 2, 586-588.

Wierda, J. L. (1943). Diverticula of the colon in rats fed on a bigh fat diet. Arch. Path., 36, 621-626. 